\title{
Статистический анализ динамики, структуры и тенденций развития алкогольной отрасли РФ
}

\author{
Д. А. Ендовицкий ${ }^{1}$ В. В. Коротких ${ }^{2 凶}$, Т. В. Яковлев ${ }^{3}$ \\ 1,2,3 Воронежский государственный университет, Университетская пл., 1, 394018, \\ Воронеж, Российская Федерация
}

Для цитирования: Ендовицкий Д. А., Коротких В. В., Яковлев Т. В. Статистический анализ динамики, структуры и тенденций развития алкогольной отрасли РФ // Вестник Воронежского государственного университета. Серия: Экономика и управление. 2020. № 4. C. 30-42. DOI: 10.17308/ econ.2020.4/3190

Предмет. Будучи одним из важнейших источников финансирования государственного бюджета, алкогольная отрасль представляет особый интерес как объект для экономического анализа. Любое вмешательство в ее деятельность имеет вполне очевидные краткосрочные эффекты и, как правило, менее предсказуемые долгосрочные последствия, которые могут оказать пагубное воздействие на социально-экономическое развитие государства.

Цели. Статистический анализ динамики, структуры и тенденций развития алкогольной отрасли РФ и выявление факторов, оказывающих влияние на деятельность организаций алкогольной отрасли в условиях кризиса.

Метод. В процессе исследования использовались параметрические методы анализа данных и машинного обучения, метод описания, анализа и синтеза, метод изучения документов и результатов деятельности.

Результаты. В исследуемом периоде в значительной степени усилился контроль государства над сферой производства, хранения, поставок алкогольной продукции, что в определенной степени соответствует глобальной политике количественного ограничения и повышения качества (культуры) потребления алкогольной продукции. Обнаружены признаки перехода от модели потребления «северного типа» к «центрально-европейской». Выявлены тенденции в динамике объемов промышленного производства и розничных продаж алкогольной продукции, особое внимание уделено оценке структурных сдвигов в период активной фазы антиалкогольной реформы. Изменения в акцизной политике государства привели к увеличению нагрузки на производителей и товаропроводящую инфраструктуру. Спад в производстве и потреблении наблюдался практически по всем укрупненным группам алкогольной продукции. Установлено, что реализуемая акцизная политика в разной степени влияет на объем производства и розничных продаж укрупненных групп алкогольной продукции. Наиболее чувствительна к изменению акцизов крепкая алкогольная продукция, наименее чувствительна - винодельческая, производство которой в период рецессии только набрало обороты. Очевидно существование рисков, порождаемых агрессивной акцизной политикой и политикой лимитирования цен, которые могут привести к дестабилизации рынка и отрасли, а также вытеснению капитала в теневой сектор.

Ключевые слова: акциз, антиалкогольная политика, алкогольная продукция.

\section{Введение}

Алкогольная отрасль является одной из традиционных в экономике РФ. Ее экономическую и социальную значимость для государства трудно переоценить. В структуре пищевой промышленности нашей страны данная отрасль стабильно занимает высокий удельный вес. Деятельность алкогольной отрасли создает экономические, социальные, культурные и другие виды эффектов, оказывая влияние на различные сферы жизни общества. Анализ состояния алкогольной отрасли является необходимым для оценки эффективности ее развития как с точки зрения обеспечения экономического роста и продовольственной безопасности государства, так и с точки зрения

(c) Ендовицкий Д. А., Коротких В. В., Яковлев Т. В., 2020

Вестник ВГУ. Серия: Экономика и управление. 2020. № 4. С. 30-42. 
обеспечения защиты здоровья граждан. Многоаспектность структуры и специфики функционирования алкогольной отрасли перманентно поддерживает на высоком уровне научный интерес исследователей по целому ряду научных направлений. Однако все они в той или иной степени затрагивают экономический аспект.

Исследователи уделяют значительное внимание проблемам государственного регулирования алкогольной отрасли. Так, М. Б. Латынцева [11] в ходе анализа текущего состояния и выявления проблем развития рынка алкогольной продукции в РФ указывает на необходимость разработки и реализации таких методов регулирования в отрасли, которые отвечали бы в первую очередь требованиям социально-экономической значимости, а не только преследовали цель эксплуатации отрасли исключительно для пополнения доходной части бюджета. В свою очередь в работе О. С. Шауриной и др. [21] ключевыми задачами регулирования производства и оборота алкогольной продукции представляются сокращение теневого рынка алкоголя, защита здоровья населения, снижение уровня потребления алкогольной продукции при сохранении экономической эффективности и наполнения федерального бюджета акцизами от производства легального алкоголя. С. Ю. Мустафина [13] выявила особенности производственного сегмента алкогольной отрасли и его роль в обеспечении продовольственной безопасности государства. С. В.Аксютина и Н. М. Овсянкина [10] изучали региональный аспект продовольственной безопасности. Особое внимание в работе уделено эффектам внедрения Единой государственной автоматизированной информационной системы учета объема производства и оборота этилового спирта, алкогольной и спиртосодержащей продукции (ЕГАИС) как в направлении борьбы с контрафактом, так и в создания благоприятных условий развития отрасли в целом.

Целью настоящего исследования является статистический анализ динамики, структуры и тенденций развития алкогольной отрасли РФ и выявление факторов, оказывающих влияние на деятельность организаций алкогольной отрасли в условиях кризиса.

В представленном исследовании решены следующие задачи:

- идентифицированы актуальные тенденции развития алкогольной отрасли в целом;
- исследованы особенности развития алкогольной отрасли в разрезе укрупненных продуктовых групп;

- определены ключевые детерминанты этих тенденций;

- сформулированы основные проблемы, наблюдаемые в алкогольной отрасли на современном этапе ее развития.

\section{Методология исследования и источники данных}

Прикладной характер исследования требует привлечения информации из разнообразных источников:

1) базы данных Росстата ${ }^{1}$; базы ведомственной статистики ${ }^{2}$, в том числе данные Федеральной налоговой службы, Федеральной службы по регулированию алкогольного рынка, Федеральной службы по надзору в сфере защиты прав потребителей и благополучия человека;

2) обзоры российского рынка алкогольной продукции ${ }^{3}$, подготовленные аналитическим центром при Правительстве РФ;

3) статистические сборники ${ }^{4}$ «Основные показатели, характеризующие рынок алкогольной продукции», подготовленные Федеральной службой по регулированию алкогольного рынка;

4) отчеты Всемирной организации здоровья ${ }^{5}: 2001$ Global Status Report on Alcohol and Young People; 2002 Global Alcohol Policy survey; 2004 Global Status Report on Alcohol, including Country Profiles; 2008 Global Survey on Alcohol and Health; 2009 Global Status Report on Alcohol and Health (consumption, harm and policy integrated), including Country Profiles; 2010 Global Survey on Alcohol and Health; 2013 Global Status Report on Alcohol and Health, including Country Profiles; 2018 Global Survey on Alcohol and Health; база данных «Здоровье для всех» (HFA-DB).

5) данные Организации экономического сотрудничества и развития ${ }^{6}(\mathrm{OECD})$.

Основными методами, которые были использованы в настоящем исследовании, являются параметрические методы анализа данных и машинного обучения, метод описания, анализа и синтеза, метод изучения документов и результатов деятельности.

\footnotetext{
${ }^{1}$ URL: https://rosstat.gov.ru/

${ }^{2}$ URL: https://fedstat.ru

${ }^{3}$ URL: https://ac.gov.ru

${ }^{4}$ URL: https://fsrar.gov.ru

${ }^{5}$ URL: https://www.who.int

${ }^{6}$ URL: https://data.oecd.org/healthrisk/alcoholconsumption.htm
} 


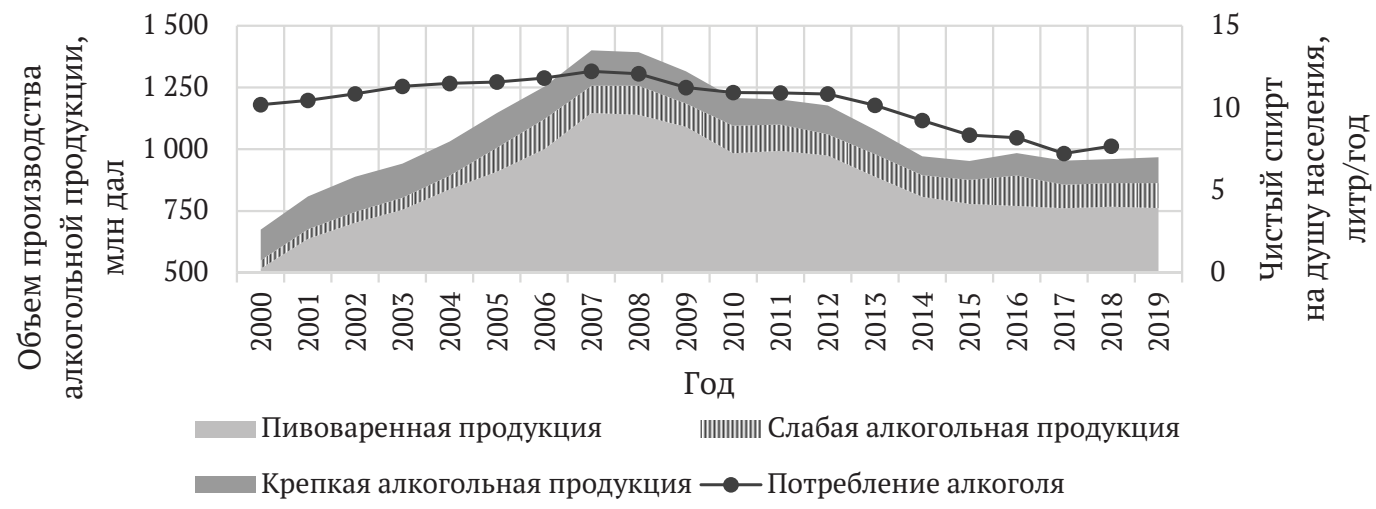

Puc. 1. Динамика и структура производства и потребления алкогольной продукции в РФ, 2000-2019 гг. (источник: Росстат, РАР, HFA-DB)

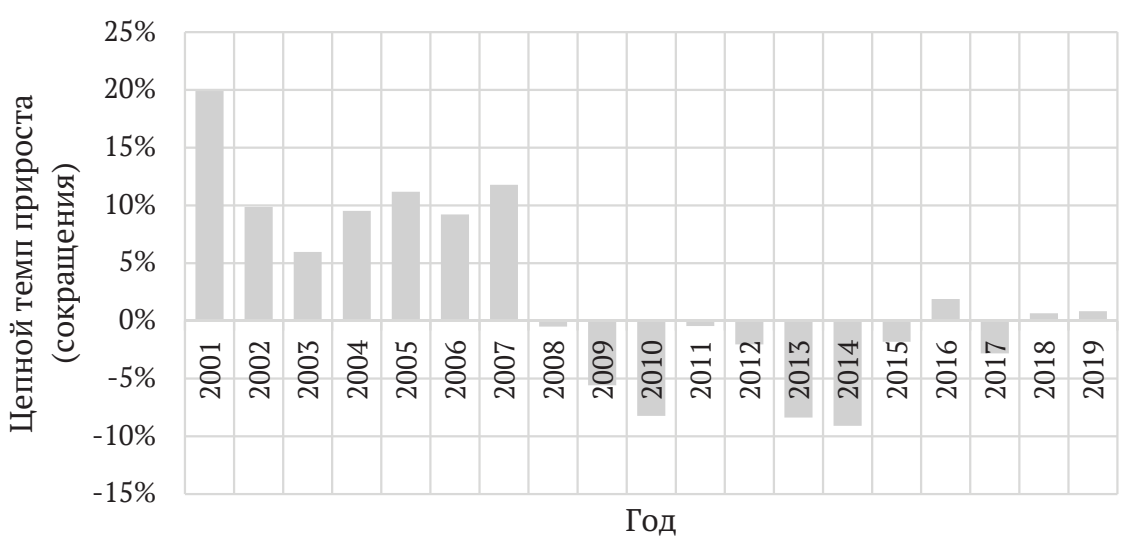

Puc. 2. Темпы прироста (сокращения) объемов производства продукции алкогольной отрасли РФ, 2001-2019 гг.

\section{Основные этапы развития алкогольной отрасли РФ в целом}

Согласно Федеральному закону № 171-ФЗ РФ ${ }^{7}$ алкогольной продукцией признается пищевая продукция, которая произведена с использованием или без использования этилового спирта, произведенного из пищевого сырья, и (или) спиртосодержащей пищевой продукции, с содержанием этилового спирта более 0,5 \% объема готовой продукции, за исключением пищевой продукции, находящейся в перечне ${ }^{8}$. Вся алкогольная продукция подразделяется: на

${ }^{7}$ Федеральный закон от 22.11.1995 № 171-Ф3 (ред. от 01.05.2019) «О государственном регулировании производства и оборота этилового спирта, алкогольной и спиртосодержащей продукции и об ограничении потребления (распития) алкогольной продукции», глава 1, статья 2, пункт 7.

${ }^{8}$ Постановление Правительства РФ от 09.11.2017 № 1344 «Об утверждении перечней пищевой продукции, которая произведена с использованием или без использования этилового спирта, произведенного из пищевого сырья, и (или) спиртосодержащей пищевой продукции, с содержанием этилового спирта более 0,5 процента объема готовой продукции, не относящейся к алкогольной продукции». спиртные напитки (в том числе водка, коньяк); вино, фруктовое вино, ликерное вино, игристое вино (шампанское), винные напитки; пиво и напитки, изготавливаемые на основе пива; сидр, пуаре и медовуха. При этом для пива, ввиду особенности технологии производства, не установлена норма содержания этилового спирта в готовой продукции, в отличие от других напитков. Для удобства в рамках данного исследования будем пользоваться укрупненными группами алкогольной продукции: «крепкая алкогольная продукция», «слабая алкогольная продукция» (в том числе «винодельческая продукция») и «пивоваренная продукция».

Для целей статистического анализа динамики, структуры и тенденций развития алкогольной отрасли РФ исследуемый период (20002019 гг.) разделим на два этапа: 2000-2007 гг. и 2008-2019 гг., каждый из которых рассмотрим по отдельности. Представленное разделение обусловлено не столько хронологическим принципом, сколько особенностями динамики основных показателей, характеризующих деятельность алкогольной отрасли РФ (рис. 1-2). 
Первый этап В. В. Радаев и др. [7; 15; 16] связывают с консолидацией государства и экономическим ростом, второй - с экономической рецессией и новой алкогольной политикой.

В период 2000-2008 гг. главной тенденцией в алкогольной отрасли РФ являлось наращивание объемов производства. По сравнению с базисным 2000 г. объем производства увеличился на 107,53 \% и достиг отметки в 1400,92 млн дал. Средний годовой темп прироста составил $11,06 \%$. Наибольший темп прироста наблюдался в 2001 г. и составил почти $20 \%$. Рост материального благосостояния граждан на фоне экономического роста в целом привел к снижению относительных цен на алкогольную продукцию. За этот период, по данным ВО39, потребление чистого спирта на душу населения (старше 15 лет) увеличилось почти на $20 \%$.

Динамика производства в алкогольной отрасли, наблюдаемая в 2000-2008 гг., сформировалась под действием множества факторов, в том числе и социокультурных. Среди них особое внимание в научных исследованиях придается фактору становления в РФ новой культуры потребления алкогольных напитков. В работах S. Popova et al. [6], J. Rehm et al. [8] и В. В. Радаева [17] констатируется процесс перехода от выбора крепкой алкогольной продукции, свойственного модели потребления «северного типа», к «центрально-европейской» модели потребления с характерным ей предпочтением слабой алкогольной продукции, в том числе пивоваренной. На этом фоне структура производства в отрасли претерпела определенные изменения: крепкие алкогольные напитки уступили место легким алкогольным напиткам, пиву и пивным напиткам.

Отличительной особенностью периода экономической рецессии и новой алкогольной политики является кардинальная смена основной тенденции в отрасли с увеличения на сокращение объемов производства почти по всем продуктовым группам. Взяв в качестве базисного 2007 г., можно убедиться, что средний годовой темп сокращения производства к 2019 г. составил 2,96 \%. За период 2008-2019 гг. спад производства в отрасли составил 30,88 \%. Минимальное значение произведенной алкогольной продукции, 954,05 млн дал, наблюдалось в 2017 г., что на 31,90\% меньше, чем в базисном.

Основным фактором, который послужил причиной такой резкой смены характера динамики в алкогольной отрасли РФ с повышатель-

${ }^{9}$ Global Information System on Alcohol and Health. URL: https://apps.who.int/gho/data/node.main.GISAH ного на понижательный, помимо собственно разворачивающейся экономической рецессии, можно указать начало активной фазы антиалкогольной реформы, включающее изменение механизмов государственного регулирования деятельности отрасли. Возрастание интереса властей к алкогольной отрасли обусловлено в первую очередь ее спецификой, а именно, как акцентирует М. Б. Латынцева [11], «двойственностью ее природы». С одной стороны, как, в частности, отмечается в исследовании Н. А. Романович [18], алкогольная промышленность и связанные с ней рынки крайне важны как источник финансирования государственного бюджета. Речь идет об акцизе на производство алкоголя, занимающего значительную долю в розничной цене. С другой стороны, в работах А. В. Немцова [2; 3; 4], А. Л. Оганесянц [14; 15] и A. Stickley et al. [9] отмечается, что стимулирование рынка алкогольной продукции и повышение доступности алкогольной продукции приводит к негативным последствиям для здоровья и благосостояния граждан.

Далее рассмотрим результаты подобного анализа в разрезе выделенных укрупненных групп алкогольной продукции в период реализации активных мер государственного регулирования в 2009-2019 гг.

\section{Крепкая алкогольная продукция}

Период 2007-2019 гг. (рис. 3) характеризуется постоянным ростом акцизов на алкогольную продукцию. В частности, рост величины акциза на водку составил 2,73 раз (с 191 руб. до 523 руб./л безводного этилового спирта). На этом фоне производство крепкой алкогольной продукции сократилось на 27 \% (до 104,91 млн дал в 2019 г.), а объемов розничных продаж - почти на 50 \% (со 193,5 млн дал в 2007 г.до 98,89 млн дал в 2019 г.).

Акцизная политика государства нашла отражение и в политике лимитирования цен на основные виды крепкой алкогольной продукции. Двукратное повышение претерпели как минимальные розничные цены (далее - МРЦ), так и средние потребительские цены (далее - СПЦ) (рис. 4). В частности, МРЦ выросла в 2,42 раза (с 89 до 215 руб./0,5 л водки), СПЦ на водку крепостью 40 \% показали рост в 2,88 раза (с 213,84 до 615,60 руб. за 1 л водки).

Проведем регрессионный анализ и постараемся получить более точные количественные оценки, характеризующие влияние акцизов на объем производства, розничных продаж и СПЦ на основные виды крепкой алкогольной продукции (табл. 1). 

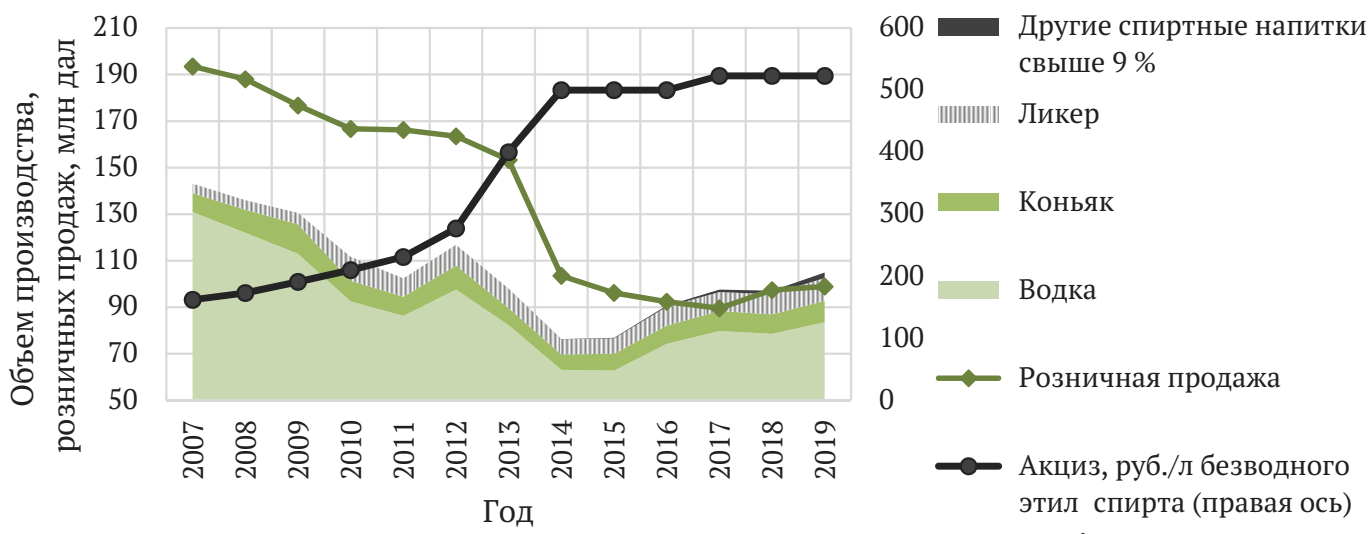

Puc. 3. Динамика и структура производства, розничные продажи и ставка акциза крепкой алкогольной продукции в РФ, 2007-2019 гг. (источник: Росстат, ФНС, РАР)

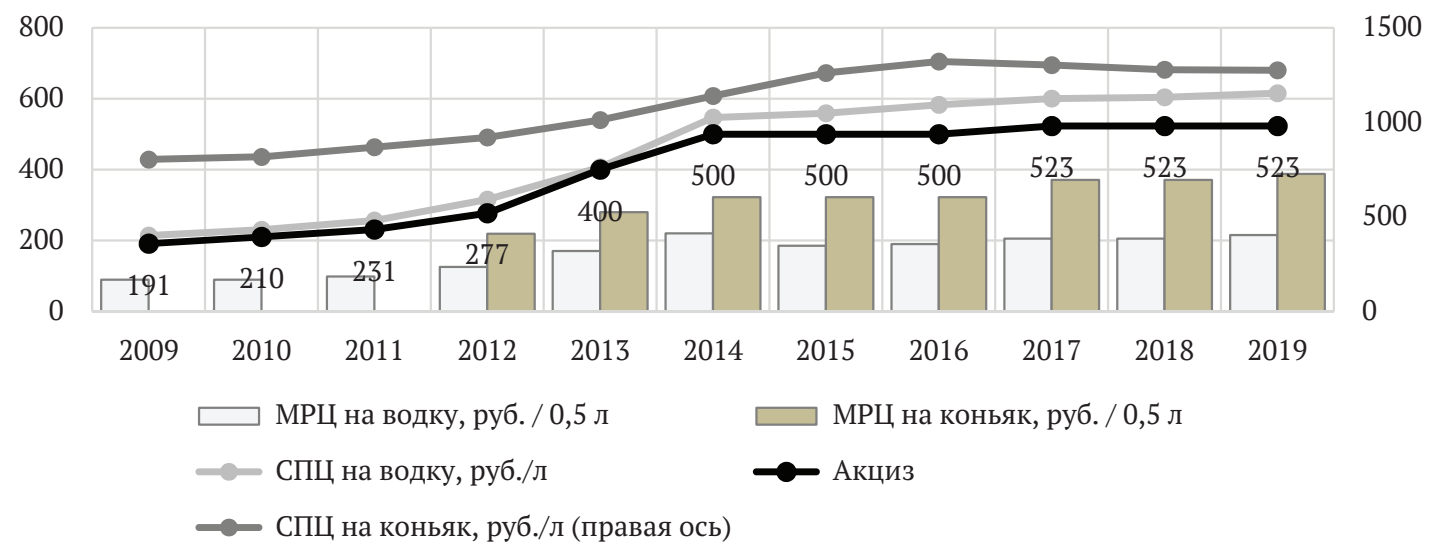

Puc. 4. Ставка акциза на крепкую алкогольную продукцию, МРЦ, СПЦ на водку и коньяк, 2009-2019 гг. (источник: Росстат, ФНС, РАР)

Т а бл иц а 1

Анализ влияния величины акциза на объем производства, розничных продаж и СПЦ крепкой алкогольной продукции, 2001-2019 гг.

\begin{tabular}{|c|c|c|c|c|}
\hline Показатель & Объем производства & $\begin{array}{c}\text { Объем } \\
\text { розничных продаж }\end{array}$ & $\begin{array}{c}\text { СПЦ } \\
\text { на коньяк }\end{array}$ & $\begin{array}{c}\text { СПЦ } \\
\text { на водку }\end{array}$ \\
\hline Intercept & $150,338^{* * * * *}$ & $243,018^{* * * * *}$ & $337,592^{* * * * *}$ & - \\
\hline Акциз, руб./л & $-0,119^{* * * * *}$ & $-0,284^{* * * *}$ & $1,840^{* * * *}$ & $1,127^{* * * *}$ \\
\hline $\mathrm{R}^{2}$ & 0,803 & 0,961 & 0,939 & 0,998 \\
\hline $\begin{array}{c}\text { Число } \\
\text { наблюдений }\end{array}$ & 17 & 17 & 17 & 17 \\
\hline
\end{tabular}

П р и м е ч а н и е: статистическая значимость на $1 \%(* * *), 5 \%$ (**), $10 \%$ (*). Источник данных: Росстат, ФНС.

Наблюдаемое снижение объемов производства крепкой алкогольной продукции почти на 80 \% обусловлено изменениями величины акцизов. Увеличение акциза на 1 руб. в среднем снижает объем производства крепкой алкогольной продукции на 0,119 млн дал.

Официальные розничные продажи крепкой алкогольной продукции оказались более чувствительны к изменению акциза. При увели- чении акциза на 1 руб. розничные продажи крепкой алкогольной продукции в среднем снижаются на 0,284 млн дал, что почти втрое быстрее, чем объем производства.

Анализ СПЦ на водку и коньяки выявил их сильную линейную зависимость от величины акциза. Цена на коньяк оказалась более чувствительной к повышению акцизов, в среднем она увеличивается на 1,84 руб. при увеличении 


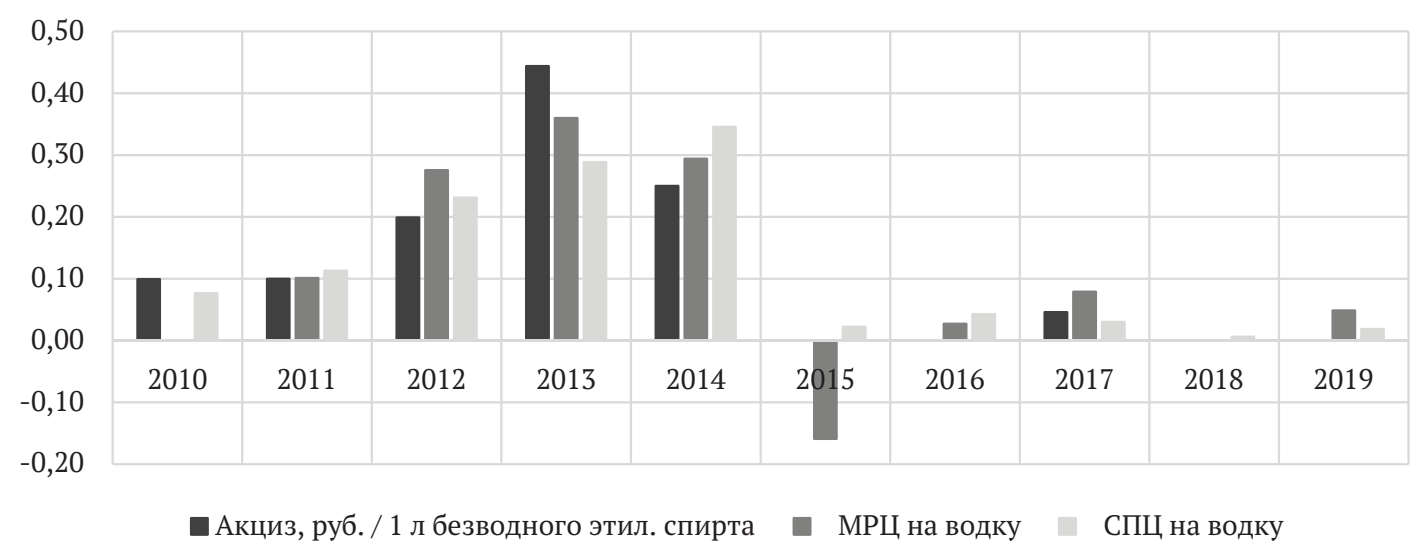

Puc. 5. Темпы прироста величины акциза, минимальной розничной и средней потребительской цены на водку

акциза на 1 руб., а цена на водку увеличивается только на 1,16 руб. Интересно также отметить, что отношения СПЦ к величине акциза для водки и коньяков разное. Для водки в исследуемом периоде времени оно составляет в среднем 0,91 (варьируется в диапазоне от 0,85 до 0,99), а для коньяков - всего 0,31 (варьируется в диапазоне от 0,23 до 0,44).

В течение 2010-2014 гг. МРЦ и СПЦ на водку в среднем росли более высокими темпами, чем величина акциза (рис. 5).

Снижение МРЦ в 2015 г. и поддержание низких значений ее темпов прироста наряду с фиксацией величины акциза в 2014 г. сумели затормозить рост и стабилизировать уровень СПЦ на водку, а также объемы производства и розничных продаж крепкой алкогольной продукции в целом.

\section{Слабая алкогольная продукция}

По сравнению с историческим максимумом в 2008 г. объем производства слабой алкогольной продукции к 2019 г. сократился на 14 \% - до 101,32 млн дал. Акциз на алкогольную продукцию с объемной долей этилового спирта до $9 \%$ вырос почти в 4 раза и к 2019 г. достиг значения 418 руб. / 1 л. Повышение акциза сопровождается снижением как объемов производства, так и объемов продаж слабых алкогольных напитков в целом (рис. 6).

Интересно отметить, что винодельческая продукция оказалась единственной, по которой в течение периода 2008-2019 гг. наблюдался рост производства на $16 \%$ - до 87,27 млн дал. Исторический максимум по объему производства винодельческой продукции был достигнут в 2016 г. и составил 90,59 млн дал (рис. 7).

Рассмотрим анализ влияния акцизной политики на показатели производства и розничных продаж в натуральном выражении (табл. 2). Как производство, так и розничные продажи винодельческой продукции демонстрируют слабую обусловленность величиной акциза на натуральные вина в отличие от крепких алкогольных напитков.
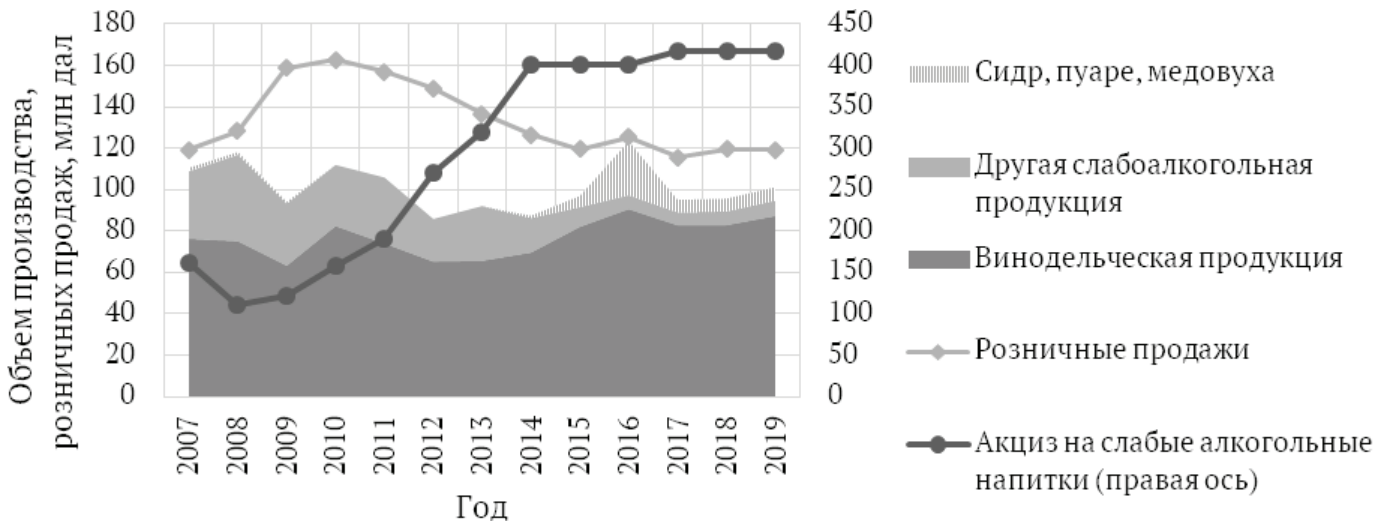

Puc. 6. Динамика и структура производства, розничные продажи и ставка акциза слабой алкогольной продукции в РФ, 2007-2019 гг. (источник: Росстат, ФНС, РАР) 


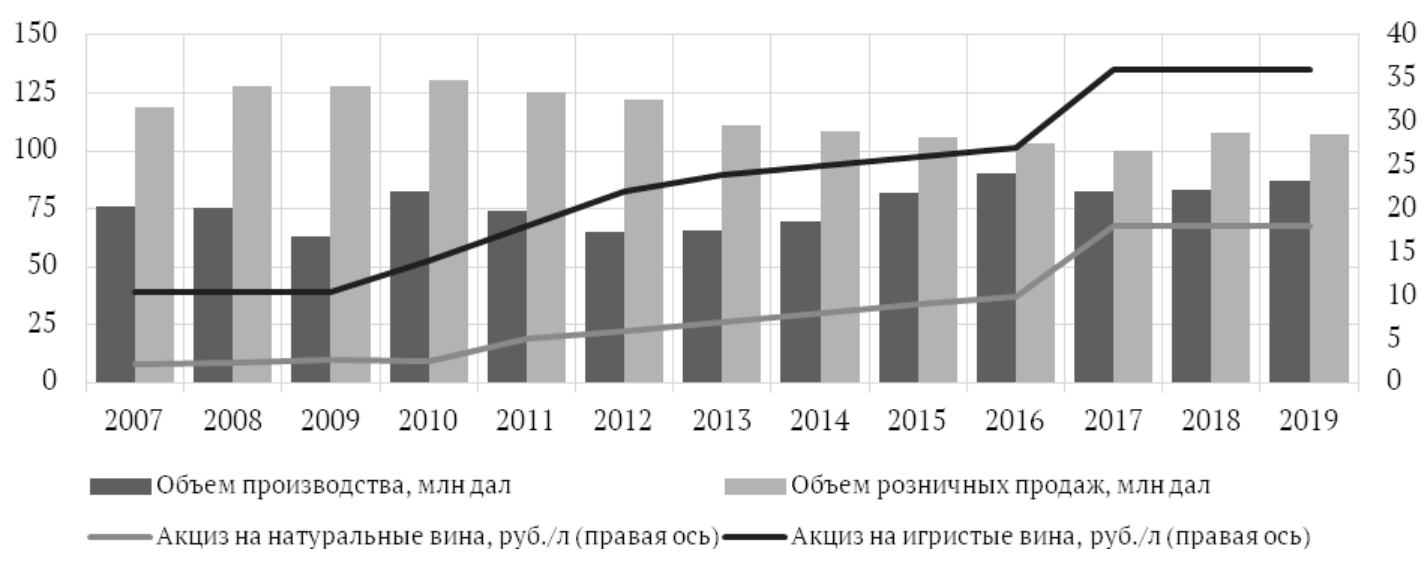

Puc. 7. Объем производства, розничных продаж и ставка акциза винодельческой продукции в РФ, 2007-2019 гг. (источник: Росстат, ФНС, РАР)

Т а бл и ц а 2

Анализ влияния величины акциза на объем производства и розничных продаж винодельческой продукции, 2009-2019 г2.

\begin{tabular}{|c|c|c|}
\hline Показатель & Объем производства & Объем розничных продаж \\
\hline Intercept & $70,343^{* * * *}$ & $125,090^{* * * * *}$ \\
\hline Акциз на натуральные вина, руб./л & $0,892^{* * *}$ & $-1,390^{* * * *}$ \\
\hline$R^{2}$ & 0,313 & 0,513 \\
\hline Число наблюдений & 11 & 11 \\
\hline
\end{tabular}

П р и м е ч а н и е: статистическая значимость на $1 \%\left({ }^{* * * *}\right), 5 \%(* *), 10 \%(*)$.

И с т о чн и к д а н ны х: Росстат, ФНС.

Таким образом, мы можем констатировать, что величина акциза не является единственным определяющим фактором для данных показателей. Кроме того, объем производства имеет тенденцию к увеличению по мере роста величины акциза. Как и для крепкой алкогольной продукции, объем розничных продаж винодельческой продукции снижается в ответ на увеличение соответствующего акциза.

\section{Пивоваренная продукция}

Пивоваренная продукция на всем исследуемом периоде (2000-2019 гг.) занимает наибольшую долю в объеме продукции, производимой алкогольной отраслью. С 20072008 гг. объемы производства пивоваренной продукции начинают снижаться. Рассматривая в качестве базисного 2009 г., можно наблюдать сокращение производства на 30 \% (с 1091,10 до 762,13 млн дал) (рис. 8). Тем не менее в 2019 г. объем сегмента пивоваренной продукции, равный 762,13 млн дал, составил 78 \% всего произведенного на территории РФ алкоголя.

В качестве основных причин понижательной динамики производства и рознич-

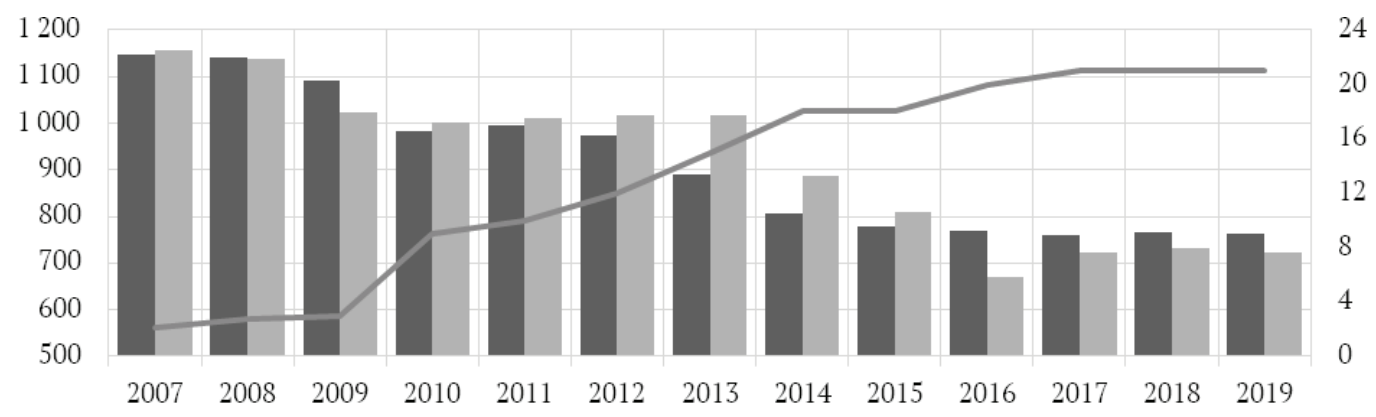

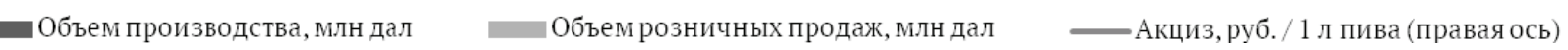

Puс. 8. Объем производства, розничных продаж и ставка акциза пивоваренной продукции в РФ, 2009-2019 гг. (источник: Росстат, ФНС, РАР) 
Статистический анализ динамики, структуры и тенденций развития алкогольной отрасли РФ

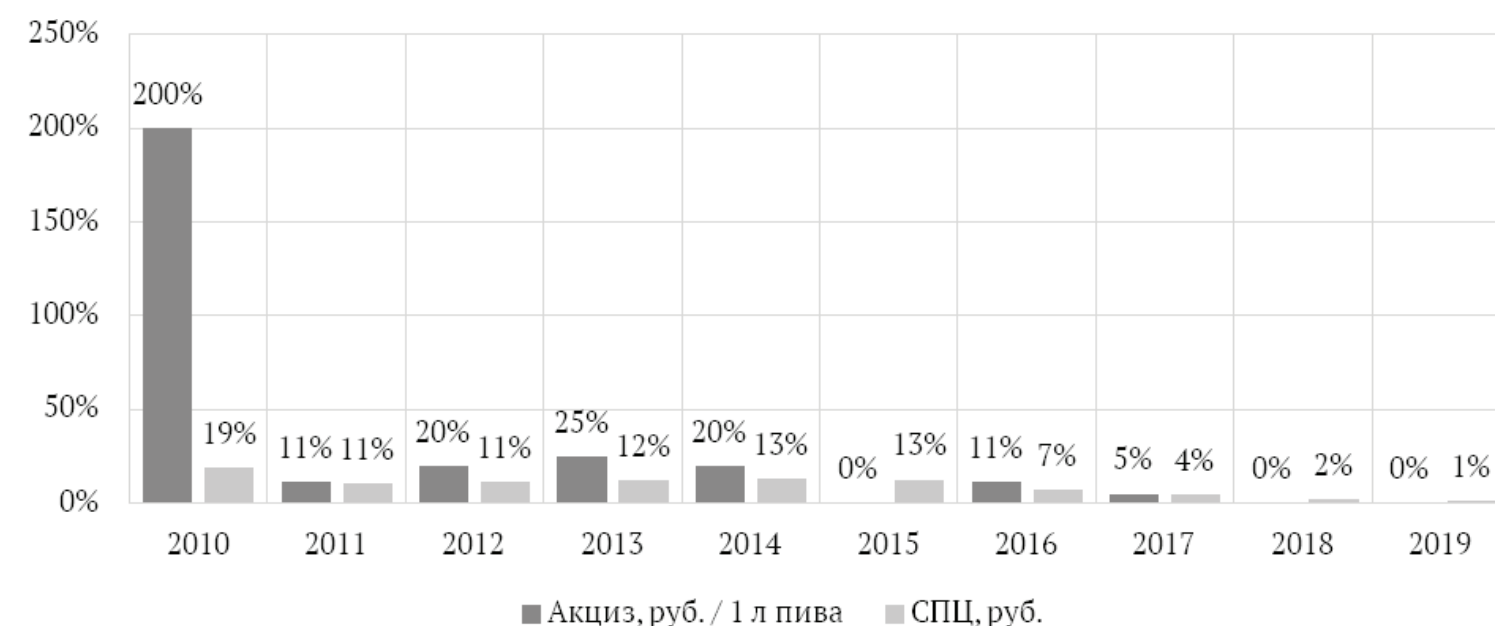

Puc. 9. Ставка акциза, СПЦ на пивоваренную продукцию, 2009-2019 гг.

Т а бл и ц а 3

Анализ влияния величины акциза на объем производства, розничных продаж и среднюю потребительскую цзену пивной продукции

\begin{tabular}{|c|c|c|c|}
\hline Показатель & Объем производства & Объем розничных продаж & $\begin{array}{c}\text { Средняя } \\
\text { потребительская цена }\end{array}$ \\
\hline Intercept & $1182,728^{* * * * *}$ & $1193,647^{* * * * *}$ & $24,195^{* * * * *}$ \\
\hline Акциз, руб./л & $-20,297^{* * * *}$ & $-20,877^{* * * *}$ & $4,005^{* * * * *}$ \\
\hline$R^{2}$ & 0,982 & 0,837 & 0,977 \\
\hline Число наблюдений & $11(2007-2019)$ & $11(2007-2019)$ & 17 \\
\hline
\end{tabular}

Примечание: статистическая значимость на $1 \%$ (***), 5 \% (**), 10 \% (*).

Источник данных: Росстат, ФНС.

ных продаж в натуральном выражении С. Ю. Мустафина [13] отмечает приостановку действия лицензий, перелицензирование крупных производителей и акцизную политику государства. За период 2009-2019 гг. акциз на пивоваренную продукцию увеличился ровно в 7 раз (с 3 до 21 руб.). При этом СРЦ на пивоваренную продукцию увеличились лишь в 2,42 раза (рис. 9). Величина и структура розничной цены пивоваренной продукции в значительной степени обусловлены масштабом производства. Себестоимость пивоваренной продукции для крупных, средних и малых пивоваренных компаний значимо различается. По данным опроса ${ }^{10}$ производителей пива в бюджетном и среднем ценовом сегменте, в 2018 г. акциз занимал в структуре розничной цены 1 л пива от 24 до 27 \%. По данным Росстата мы оценили, что в период 2001-2019 гг. доля акциза в структуре средней потребительской

\footnotetext{
${ }^{10}$ URL: https://profibeer.ru/law/31881/
}

цены на пивоваренную продукцию не превышала 21 \% (значение 2014 г.) и в среднем составляла около $12 \%$.

В ходе исследования зависимости объемов производства пивоваренной продукции от величины акциза установлено, что при увеличении акциза на 1 руб., производство снижалось в среднем на 20,3 млн дал в год (табл. 3). Исходя из значения коэффициента детерминации $\left(R^{2}=0,982\right)$, можно предположить, что именно повышение акциза оказывает сильнейшее давление на объем производства. При увеличении акциза на 1 руб. розничные продажи сокращались в среднем на 20,9 млн дал в год, хотя общая вариация объема розничных продаж изменения несколько хуже объясняется изменением акциза $\left(R^{2}=0,837\right)$. Кроме того, в исследовании установлено, что акциз также является основным фактором формирования средней потребительской цены на пивоваренную продукцию. При повышении акциза на 1 руб. величина средней потребительской цены возрастает на 4,01 руб. 


\section{Обсуждение результатов}

Акцизная политика государства привела к необходимости повышения отпускных цен, увеличению нагрузки на производителей и товаропроводящую инфраструктуру. Если зависимость объемов производства алкогольной продукции от размеров акциза очевидна, то ряд исследователей (см. напр.: Z. Kotelnikova [1]; M. Neufeld и J. Rehm [5]; М. И. Левин и А. Б. Фенько [12]; А. С. Скоробогатов [20]) видят влияние акцизов на величину потребление алкогольной продукции на душу населения в литрах чистого спирта не столь однозначным (табл. 4).

Наблюдаемое снижение уровня официального потребления алкогольной продукции происходит не столько за счет снижения собственно общего уровня потребления, сколько за счет переключения потребительского спроса в теневой сектор алкогольного рынка.

Единство норм регулирования рынка алкогольной продукции, как правило, не в состоянии обеспечить получение одинаковых эффектов на легальном и теневом сегментах рынка. Основываясь на результатах Р. Ю. Скокова [19], можно с определенной долей уверенности сказать, что большинство реализуемых мер государственного регулирования, например увеличение акцизов, лимитирование цен на уровне производства, оптовой и розничной торговли, ограничение мест и времени продаж, не только напрямую затрагивают деятельность всех участников легального рынка, но и неявно создают недобросовестным участникам рынка дополнительные выгоды от ведения их деятельности. В. В. Радаев и др. [7; 16] отмечают, что легальный и теневой сегменты рынка алкогольной продукции развиваются в соответствии с собственной логикой, с связи с чем при разработке контрольных и регулирующих действий на каждом из этих сегментов следует учитывать закономерности их функционирования.

\section{Заключение}

В работе представлены результаты статистического анализа динамики, структуры и тенденций развития алкогольной отрасли РФ в период 2000-2019 гг. с выделением двух этапов. Для этапа консолидации государства и экономического роста (2000-2007 гг.) характерно наращивание объемов производства (ежегодно в среднем на 11,06 \%) и потребления алкогольной продукции, а также изменение культуры потребления алкогольных напитков.

Для этапа экономической рецессии и новой алкогольной политики (2008-2019 гг.) характерна кардинальная смена основных тенденций в отрасли, обусловленная началом активной фазы антиалкогольной реформы. Реформа включает изменение механизмов государственного регулирования деятельности отрасли. Изменения в акцизной политике государства привели к увеличению нагрузки на производителей и товаропроводящую инфраструктуру. Спад в производстве и потреблении наблюдался практически по всем укрупненным группам алкогольной продукции.

Вопреки сложившейся в алкогольной отрасли обратной зависимости объемов производства продукции в натуральном выражении и величины акциза объем производства именно винодельческой продукции не следует этой закономерности. Кроме того, доля его вариации, объясненной изменением величины акциза, не превышает 34 \%, что свидетельствует о низкой чувствительности к рискам повышения величины акциза в будущем. В объеме розничных продаж винодельческой продукции в натуральном выражении аномалий по отношению к отраслевым закономерностям не выявлено, доля его вариации, объясненной изменением акцизов, немногим более $50 \%$.

По сравнению с розничными продажами производство крепкой алкогольной продукции

Т а бл и ц а 4

Анализ зависимости ежегодного потребления алкогольной продукции от величины акциза в РФ, 2007-2019 г2.

\begin{tabular}{|c|c|c|c|}
\hline \multirow{2}{*}{ Показатель } & \multicolumn{3}{|c|}{ Потребление по группам алкогольной продукции } \\
\cline { 2 - 4 } & Крепкая & Винодельческая & Пивоваренная \\
\hline Intercept & $7,394^{* * * * *}$ & $1,248^{* * * * *}$ & $4,758^{* * * * *}$ \\
\hline Акциз, руб./л & $-0,008^{* * * *}$ & $-0,009^{* * * *}$ & $-0,061^{* * * *}$ \\
\hline$R^{2}$ & 0,948 & 0,486 & 0,775 \\
\hline Число наблюдений & 10 & 10 & 10 \\
\hline
\end{tabular}

П р и м е ч а н и е: статистическая значимость на $1 \%\left({ }^{* * * *}\right), 5 \%$ (**), $10 \%$ (*).

Источник данных: OECD, GISAH, ФНС. 
в натуральном выражении оказалось менее чувствительным к изменению величины акциза. Средняя потребительская цена основных видов крепкого алкоголя демонстрирует сильную линейную зависимость от величины акциза. Коэффициент абсолютного роста средней потребительской цены на коньяк превышает соответствующий коэффициент для водки на 30 \%. Лимитирование цен и рост доли акцизов в структуре цены способствуют повышению уязвимости легального рынка и создают дополнительные выгоды для недобросовестных участников, поскольку при минимальной себестоимости производства сбыт продукции в теневых каналах становится все более рентабельным. В связи с этим есть основания полагать, что снижение уровня официального потребления крепкой алкогольной продукции произошло в основном за счет переключения потребительского спроса в теневой сектор алкогольного рынка.

На всем исследуемом промежутке времени пивоваренная продукция занимает наибольший удельный вес в объеме продукции алкогольной отрасли. Семикратный рост величины акциза на пивоваренную продукцию сопровождался более чем двукратным ростом средней потребительской цены. При этом под влиянием роста акцизов объемы производства и розничных продаж пивоваренной продукции снижались в равной степени - на 20-21 млн дал при росте акциза на 1 руб. Следует отметить, что вариация объема производства может быть

\section{Библиографический список}

1. Kotelnikova Z. Explaining Counterfeit Alcohol Purchases in Russia // Alcoholism : Clinical and Experimental Research. 2017. Vol. 41 (4). P. 810-819.

2. Nemtsov A. V. A Contemporary History of Alcohol in Russia. Stockholm, Sweden : Södersröms högskola. 2011.

3. Nemtsov A. V. Alcohol consumption in Russia: Is monitoring health in the Russia Federation (RLMS) trustworthy? // Addiction. 2003. No. 98. P. 386-388.

4. Nemtsov A. V. Alcohol consumption level in Russia: a viewpoint on moni-toring Health Conditions In the Russian Federation (RLMS) // Addiction. 2003. № 98. P. 369-370.

5. Neufeld M., Rehm J. Alcohol consumption and mortality in Russia since 2000: Are there any changes following the alcohol policy changes starting in 2006? // Alcohol and Alcoholism. 2013. Vol. 48/2. P. 222-230.

6. Popova S., Rehm J., Patra J., Zatonski W. Comparing alcohol consumption in central and eastern объяснена вариацией величины акциза почти на 99 \%, а вариация объема розничных продаж - лишь на 84 \%. Реакция потребителей пивоваренной продукции менее чувствительна к изменению акцизной политики по сравнению с реакцией производителей.

Таким образом, в настоящее время алкогольная отрасль РФ в целом переживает спад. Для достижения этого результата предпринимаются активные действия как со стороны государства (в основном за счет реализуемой акцизной политики на фоне декларации целого комплекса мер по регулированию алкогольного рынка), так и со стороны потребителей. Мы полагаем, что указанная тенденция должна стимулировать производителей к повышению качества производимой продукции и ее конкурентоспособности на рынке.

При этом вполне очевидны риски реализации агрессивной акцизной политики и политики лимитирования цен. Регулирование, направленное исключительно на пополнение доходной части бюджета, приводит к дестабилизации рынка и отрасли, а также вытеснению капитала в теневой сектор, что с учетом специфики рынка несет в себе угрозы как для добросовестных предприятий алкогольной отрасли, так и для потребителей продукции.

\section{Конфликт интересов}

Авторы декларируют отсутствие явных и потенциальных конфликтов интересов, связанных с публикацией настоящей статьи.

europe to othereuropean countries // Alcohol \& Alcoholism. 2007. Vol. 42, no. 5. P. 465-473.

7. Radaev V. V., Salnikova D., Roshchina Y. The Decline in Alcohol Consumption in Russia from 2006 to 2017: Do Birth Cohorts Matter? // Alcohol and Alcoholism. 2020. Vol. 55, no. 3. P. 323-335.

8. Rehm J., Rehn N., Room R. et al. The global distributionof average volume of alcohol consumption and patterns of drinking // European Addiction Research. 2003. Vol. 9. P. 147-156.

9. Stickley A., Razvodovsky Y., McKee M. Alcohol and mortality in Russia: A historical persperctive // Public Health. 2009. Vol. 123. P. 20-26.

10. Аксютина С. В., Овсянкина Н. М. Актуальные вопросы алкогольной безопасности региона // Экономические и социальные перемены: факты, тенденции, прогноз. 2015. № 1 (37). С. 117-133.

11. Латынцеева М. Б. Современное состояние рынка алкогольной продукции в России // Вестник Омского университета. Серия «Экономика». 2017. № 4 (60). С. 54-61. 
12. Левин М. И., Фенько А. Б. Экономические модели аддиктивного поведения // Финансы и бизнес. 2008. № 4 .

13. Мустафина С. Ю. Статистическое исследование производственного сегмента алкогольной отрасли в рамках обеспечения продовольственной безопасности государства // Вестник экономической безопасности. 2018. № 1. С. 331-336.

14. Оганесянц А. Л., Хуршудян С. А. Актуальные аспекты обеспечения качества алкогольной продукции России // Пиво и напитки. 2015. № 5. С. 12-14.

15. Оганесяни А. Л. Совершенствование методики установления акцизов на алкогольную продукцию // Пиво и напитки. 2015. № 3. С. 8-11.

16. Радаев В. В., Рощина Я. М. Измерение потребления алкоголя как методологическая проблема // Социология: методология, методы, математическое моделирование. 2019. № 48. С. 7-57.
17. Радаев В. В., Котельникова З. В. Изменение структуры потребления алкоголя в контексте государственной алкогольной политики в России // Экономическая политика. 2016. № 5. С. 92-117.

18. Романович Н. А. Алкоголь в России: мифы общественного мнения и реальность // Социологический журнал. 2015. Т. 21, № 3. С. 63-87.

19. Скоков Р. Ю. Развитие методологии статистического анализа рынков аддиктивных благ // Вопросы статистики. 2016. № 5. С. 63-69.

20. Скоробогатов А. С. Влияние политики ограничения ночной продажи крепкого алкоголя на потребление и злоупотребление алкоголем в России // Journal of Institutional Studies. 2016. T. 8, № 3. C. 72-90.

21. Шаурина О. С., Харчикова Н. В., Емельянова $E$. B. Современное состояние, закономерности развития и механизмы государственного регулирования алкогольного рынка в России // Фундаментальные исследования. 2020. № 1. С. 46-50.
Дмитрий Александрович Ендовицкий, доктор экономических наук, профессор, ректор, вице-президент Российского союза ректоров, Воронежский государственный университет, Воронеж, Российская Федерация

E-mail: rector@vsu.ru

ORCID ID: 0000-0002-0030-0252

Вячеслав Владимирович Коротких, кандидат экономических наук, доцент кафедры информационных технологий и математических методов в экономике, Воронежский го- сударственный университет, Воронеж, Российская Федерация

E-mail: korotkikh@econ.vsu.ru

ORCID ID: 0000-0001-9029-7466

Тимур Валентинович Яковлев, аспирант кафедры экономического анализа и аудита, Воронежский государственный университет, Воронеж, Российская Федерация

E-mail: yakovlev_tv@econ.vsu.ru

ORCID ID: 0000-0002-6828-5052

Поступила 20.10.2020

Подписана в печать 10.12.2020 


\title{
Statistical analysis of the dynamics, structure and tendencies of development of the alcoholic industry of the Russian Federation
}

\author{
D. A. Endovitsky', V. V. Korotkikh ${ }^{2}$, T. V. Yakovlev ${ }^{3}$ \\ 1,2,3 Voronezh State University, 1, University sq., 394018, Voronezh, Russian Federation
}

Cite as: Endovitsky, D. A., Korotkikh, V. V., Yakovlev, T. V. (2020) Statistical analysis of the dynamics, structure and tendencies of development of the alcoholic industry of the Russian Federation. Proceedings of Voronezh State University. Series: Economics and Management. 4, 30-42. DOI: 10.17308/econ.2020.4/3190

\begin{abstract}
Importance. The alcoholic industry is extremely interesting as an object for economic analysis as one of the most important sources of financing for the state budget. Any interference in its activities has quite obvious short-term effects and less predictable long-term consequences that can negatively affect the socio-economic development of the state.

Objectives. Statistical analysis of the dynamics, structure and development trends of the alcohol industry in the Russian Federation and the identification of factors affecting the activities of organizations in the alcohol industry during the crisis.

Method. During the research, we used parametric methods of data analysis and machine learning, descriptive method, analysis and synthesis.

Results. State control over the production, storage, and supply of alcoholic beverages has significantly increased in the period under study. This trend is due to the global policy of quantifying and increasing the culture of consumption of alcoholic beverages. The authors found signs of a shift from a "northern" to "Central European" consumption model. Significant changes took place in the dynamics of industrial production and retail sales of alcoholic beverages. The authors paid special attention to the assessment of structural changes during the active phase of the anti-alcohol reform. The observed changes in the excise policy of the state have led to an increase in the burden on producers and distribution infrastructure. A decline in production and consumption was observed practically for all enlarged groups of alcoholic beverages. The authors found that the implemented excise policy has a different effect on the volume of production and retail sales of large groups of alcoholic beverages. The production and sale of spirits is most sensitive to changes in excise taxes. The production and sales of wine products were the least sensitive. Moreover, during the recession, production showed positive dynamics. It is obvious that there are risks generated by an aggressive excise policy and a policy of price caps, which can lead to destabilization of the alcoholic beverages market, as well as the displacement of capital into the shadow sector.
\end{abstract}

Key words: excise tax, anti-alcohol policy, alcoholic beverages.

\section{Conflict of Interest}

The authors declare the absence of obvious and potential conflicts of interest related to the publication of this article.

\section{References}

1. Kotelnikova, Z. (2017) Explaining counterfeit alcohol purchases in Russia. Alcoholism : Clinical and Experimental Research. 41 (4), 810-819.

2. Nemtsov, A. V. (2011) A Contemporary History of Alcohol in Russia. - Stockholm, Sweden : Södersröms högskola.

3. Nemtsov, A. V. (2003) Alcohol consumption in Russia: Is monitoring health in the Russia Federation (RLMS) trustworthy? Addiction. 98, 386-388.

4. Nemtsov, A. V. (2003) Alcohol consumption level in Russia: A viewpoint on monitoring Health
Conditions In the Russian Federation (RLMS). Addiction. 98, 369-370.

5. Neufeld, M. \& Rehm, J. (2013) Alcohol consumption and mortality in Russia since 2000: Are there any changes following the alcohol policy changes starting in 2006? Alcohol and Alcoholism. 48(2), 222-230.

6. Popova, S., Rehm, J., Patra, J. \& Zatonski, W. (2007) Comparing alcohol consumption in central and eastern europe to othereuropean countries. Alcohol and Alcoholism. 42 (5), 465-473. 
7. Radaev, V. V., Salnikova, D. \& Roshchina Y. (2020) The Decline in Alcohol Consumption in Russia from 2006 to 2017: Do Birth Cohorts Matter? Alcohol and Alcoholism. 55 (3), 323-335.

8. Rehm, J., Rehn, N., Room, R. et al. (2003) The global distributionof average volume of alcohol consumption and patterns of drinking. European Addiction Research. 9, 147-156.

9. Stickley, A., Razvodovsky, Y., McKee, M. (2009) Alcohol and mortality in Russia: A historical persperctive. Public Health. 123, 20-26.

10. Aksyutina, S. V., Ovsyankina, N. M. (2015) Critical issues of alcohol safety in the region. Economic and Social Changes: Facts, Trends, Forecast. 1 (37), 117-133. (In Russ.)

11. Latyntseva, M. B. (2017) The current state of an alcohol market in Russia. Herald of Omsk University. Series "Economics". 4 (60), 54-61. (In Russ.).

12. Levin, M. I. \& Fenko, A. B. (2008) [Economic models of addictive behavior]. [Finance and business]. 4. (In Russ.)

13. Mustafina, S. Y. (2018) The statistical research of the production segment of the alcohol industry in the framework of food security of the state. Vestnik of economic security. 1, 331-336. (In Russ.)

14. Oganesyants, A. L. \& Khurshudyan, S. A. (2015) Actual Aspects of the Alcohol Products
Quality in Russia. Beer and beverages. 5, 12-14. (In Russ.)

15. Oganesyants, A. L. (2015) Improving Methods of Establishment Excise Taxes on Alcoholic Beverages. Beer and beverages. 3, 8-11. (In Russ.).

16. Radaev, V. V. \& Roshchina, Y. M. (2019) Measuring alcohol consumption as a methodological problem. Sociology: methodology, methods, mathematical modeling (4M). 48, 7-57. (In Russ.).

17. Radaev, V. V. \& Kotelnikova, Z. V. (2016) Changes in alcohol Consumption and Governmental alcohol Policy in Russia. Economic Policy. 5, 92-117. (In Russ.).

18. Romanovich, N. A. (2015) The alcohol in Russia: public opinion myths and reality. Sociological Journal. 21(3), 63-87. (In Russ.).

19. Skokov, R. Y. (2016) Development of the methodology for statistical analysis of markets for addictive goods. Voprosy statistiki. 5, 63-69. (In Russ.).

20. Skorobogatov, A. S. (2016) The effect of closing hour restrictions on alcohol use and abuse in Russia. Journal of Institutional Studies. 8(3), 72-90. (In Russ.).

21. Shaurina, O. S., Kharchikova, N. V. \& Emelyanova, E. V. (2020) Current state, patterns of development and mechanisms of state regulation of the alcohol market in Russia. Fundamental Research. 1, 46-50. (In Russ.).
Dmitry A. Endovitsky, Dr. Sci. (Econ.), Full Prof., Rector, Vice-President of the Russian Rector's Union, Voronezh State University, Voronezh, Russian Federation

E-mail: rector@econ.vsu.ru

ORCID ID: 0000-0002-0030-0252

Viacheslav V. Korotkikh, Cand. Sci. (Econ.), Assoc. Prof., IT and Mathematical Methods in Eco- nomics Department, Voronezh State University, Voronezh, Russian Federation

E-mail: korotkikh@econ.vsu.ru

ORCID ID: 0000-0001-9029-7466

Timur V. Yakovlev, Postgraduate student, Voronezh State University, Voronezh, Russian Federation E-mail: yakovlev_tv@econ.vsu.ru ORCID ID: 0000-0002-6828-5052

Received 20.10.2020

Accepted 10.12.2020 